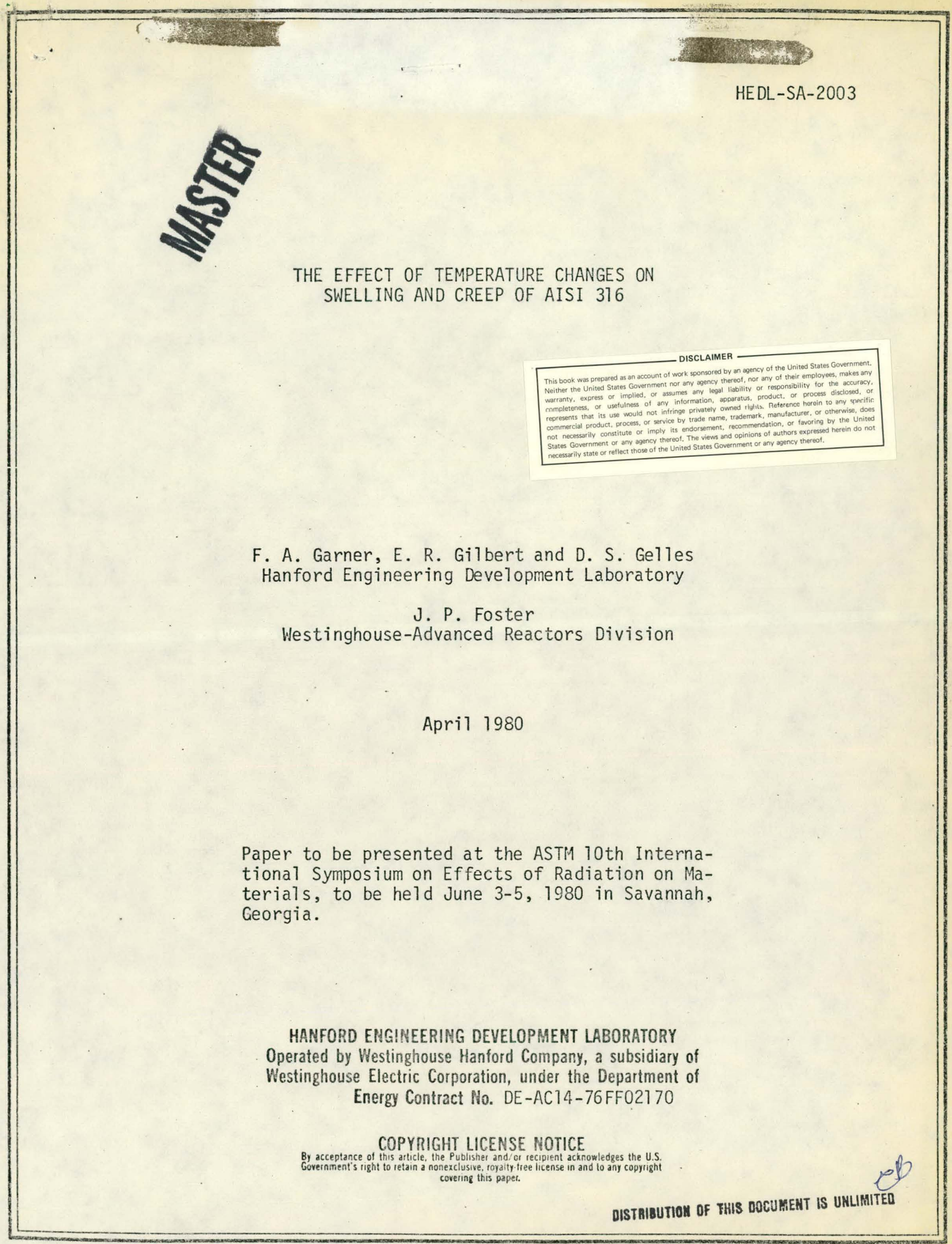




\section{DISCLAIMER}

This report was prepared as an account of work sponsored by an agency of the United States Government. Neither the United States Government nor any agency Thereof, nor any of their employees, makes any warranty, express or implied, or assumes any legal liability or responsibility for the accuracy, completeness, or usefulness of any information, apparatus, product, or process disclosed, or represents that its use would not infringe privately owned rights. Reference herein to any specific commercial product, process, or service by trade name, trademark, manufacturer, or otherwise does not necessarily constitute or imply its endorsement, recommendation, or favoring by the United States Government or any agency thereof. The views and opinions of authors expressed herein do not necessarily state or reflect those of the United States Government or any agency thereof. 


\section{DISCLAIMER}

Portions of this document may be illegible in electronic image products. Images are produced from the best available original document. 


\title{
THE EFFECT OF TEMPERATURE CHANGES ON
} SWELLING AND CREEP OF AISI 316

\author{
F. A. Garner, E. R. Gilbert, D. S. Gelles, and J. P. Foster
}

\section{ABSTRACT}

A number of previous publications have shown that the swelling of coldworked AISI 316 is quite sensitive to changes in temperature which occur during irradiation. In this report those data are expanded and reanalyzed to show that the concurrent irradiation creep is also quite sensitive to changes in irradiation temperature. An explanation is advanced to explain this behavior in terms of the sensitivity to temperature history of the radiation-induced microchemical evolution of this steel. In particular, the sensitivity to temperature history of the radiation-stabilized gamma prime phase is invoked to explain the enhanced creep and swelling behavior of AISI 316 components which experienced either gradual or abrupt decreases in temperature. The phase development observed in this steel in response to temperalure changes during irradiation is also compared to the similar behavior found in aged specimens subjected to isothermal irradiation.

INTRODUCTION

There have been three recent reports which indicate that temperature decreases during fast reactor irradiation of $20 \%$ cold-worked AISI 316 lead to an enhancement of void swelling relative to that generated by isothermal irradiation. The decreases in temperature have been abrupt, (1) gradual, (2) and cyclical ${ }^{(3)}$ in nature. Since the starting temperature was always at or below the temperature where the swelling rate was thought to peak, these results were somewhat puzzling. How could swelling be enhanced by falling through a temperature regime where the swelling rate declined? Another anomaly was observed in the abrupt temperature change experiments in that the irradiation creep rate appeared to be unaffected by the change in temperature. (1) It was expected that swelling and creep would exhibit the same beliavior since their temperature dependencies for isotherilal irradiation are similar. (4) 
These apparent anomalies have now been resolved with the discovery that temperature decreases during irradiation can alter the radiation-induced precipitation sequences that have been found to govern the instantaneous swelling and creep rates of this alloy. ${ }^{(5-7)}$ Each of the three published data sets $(1-3)$ will be reviewed in 1 ight of this discovery and additional data on the creep behavior in these experiments will be presented. The experiment involving gradual temperature changes will be reviewed first since it was in that experiment that the key to the physical process involved was discovered.

ENHANCED SWELL ING DURING GRADUAL TEMPERATURE REDUCTIONS (P-1 EXPERIMENT)

In this experiment, the alloy was irradiated in the form of small thinwalled gas-pressurized tubes used to measure irradiation creep. (2) The tëmperature fell during irradiation due to a swelling-induced closure of the gas gap between the inner and outer capsules which contained the tubes. Two sub-sets of data were published, one for starting temperatures of $525^{\circ} \mathrm{C}$ and one at $585^{\circ} \mathrm{C}$. Figure 1 . shows that the swelling in excess of the isothermal value $\left(2 \%\right.$ at $525^{\circ} \mathrm{C}$ and $4 \%$ at $585^{\circ} \mathrm{C}$ ) increases with the total temperature drop. In the data tabulated in Table 1 it should be noted that there are slight differences in the fluence attained by each specimen as well as differences in the stress level. The swelling of this alloy is known to be sensitive to both fluence and stress (E) but the enhanced swelling is too large to be attributed soley to these variations.

Figure 1 provides a clue to the identity of the causitive mechanism in the extrapolated intercepts of these curves with the temperature change axis. The intercepts are very close approximations to the difference between the original temperature and the temperature at which the $\gamma^{\prime}$ boundary occurs for the neutron fluence accumulated in the experiment. According to the work of Brager and Garner ${ }^{(5)}$ isothermal irradiation of this material should not lead to the formation of $\gamma^{\prime}$ in this heat of steel at these fluences for temperatures of 525 and $585^{\circ} \mathrm{C}$. When six of the nine specimens listed in Table 1 were examined by transmission electron microscopy, the $\gamma^{\prime}$ phase was indeed found in all six. This phase is nominally $\mathrm{Ni}_{3} \mathrm{Si}$ in composition, is formed in this alloy only during irradiation ${ }^{(5)}$ and dissolves if the radiation ceases but the temperature is maintained. (6) 


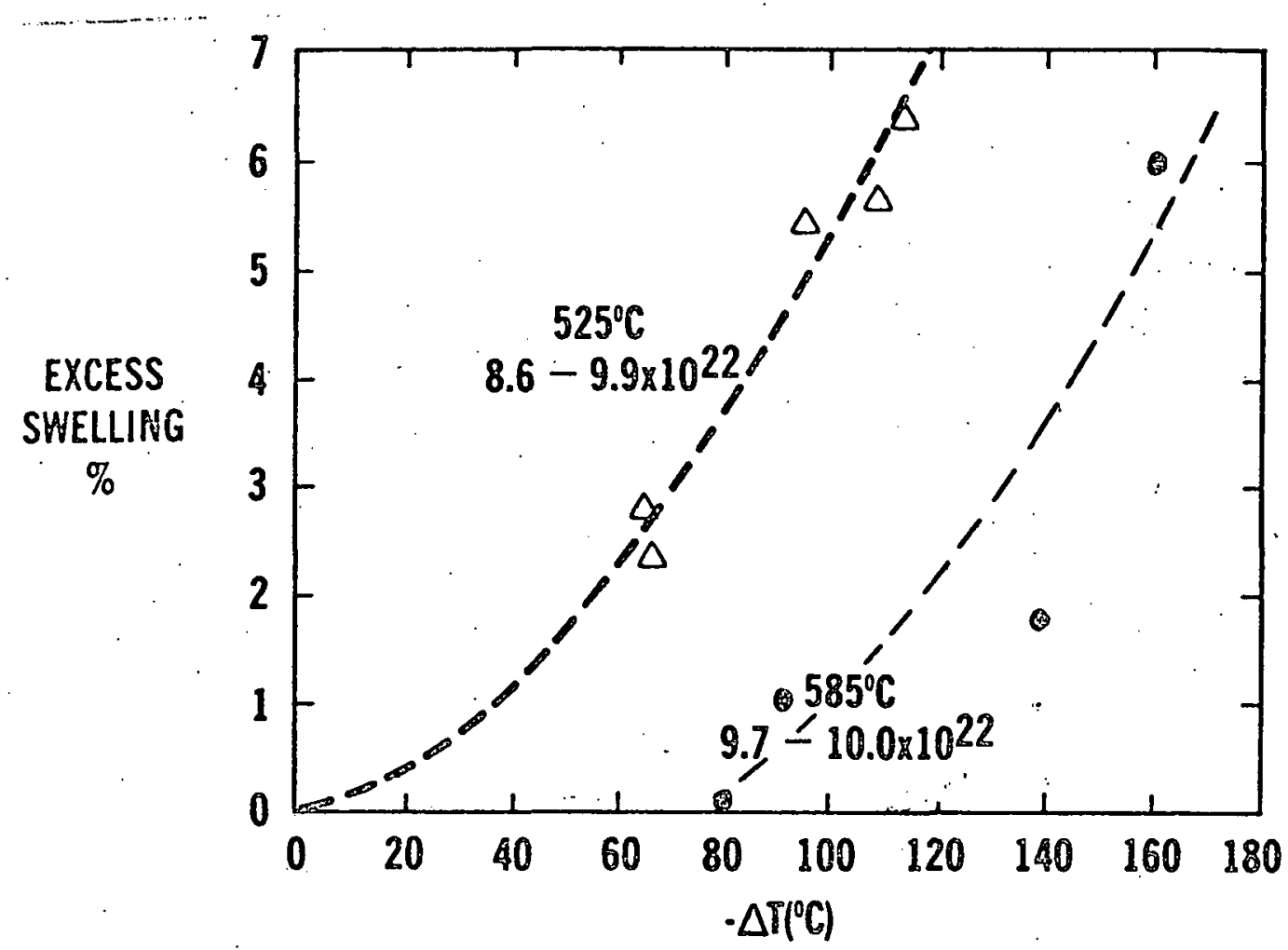

FIGURE 1. Enhancement of Swelling by Gradual Temperature Reductions During Fast Reactor Irradiation of $20 \%$ Cold-Worked AISI 316 in the P-l Experiment. (2)

TABLE 1

DATA TABULATED FOR PRESSURIZED TUBE SPECIMENS FROM THE $X$-157C EXPERIMENT UNDERGOING LARGE TEMPERATURE DROPS IN-REACTOR

\begin{tabular}{|c|c|c|c|c|c|}
\hline $\begin{array}{l}\text { Specimen } \\
\text { Identity }\end{array}$ & Irrad. Tern., & $\begin{array}{l}\Delta T \\
{ }^{\circ} \mathrm{C}\end{array}$ & $\begin{array}{l}\text { Fiuence } \\
\times \quad 10^{22} \mathrm{n} / \mathrm{cm}^{2} \\
(\Sigma>0.1 \mathrm{MeV})\end{array}$ & $\begin{array}{l}\text { Hoop } \\
\text { Stress } \\
\text { MPa }\end{array}$ & ${ }_{\mathscr{\sigma}}^{\text {Density Change }}$ \\
\hline$A n^{*}$ & $59.6-5.12$ & 79 & 10.0 & 0.0 & -4.11 \\
\hline AR & $581-442$ & 139 & 10.0 & 5.7 & -5.47 \\
\hline$B T^{*}$ & $584-423$ & 161 & 9.7 & 14.5 & -10.07 \\
\hline$B E *$ & $589-498$ & 21 & 9.9 & 28.9 & -5.03 \\
\hline$A L=$ & $528-463$. & 64 & 9.0 & 0.0 & $-4,35$ \\
\hline$B F$ & $526-431$ & 95 & 9.9 & 15.2 & -7.25 \\
\hline BP & $526-417$ & 108 & 8.6 & 29.6 & -7.70 \\
\hline$B U=$ & $523-416$ & 114 & 9.7 & 59.9 & -9.36 \\
\hline$B A^{*}$ & $524-458$ & 66 & 8.7 & 89.6 & -4.89 \\
\hline
\end{tabular}

* Selected for microstructural examination. 
Figure 2 shows the fluence/temperature regime for isothermal $\gamma^{\prime}$ formation in heats of $20 \%$ CW AISI 316 which exhibit comparable swelling behavior in EBR-II. It also shows the data of Cawthorne and Brown ${ }^{(9)}$ for $20 \% \mathrm{CW}$ M-316 stainless steel irradiated in DFR which shows a similar abrupt cut-off of $\gamma^{\prime}$ formation at temperatures around 500 to $540^{\circ} \mathrm{C}$, depending on the neutron fluence. Note that all data points on this diagram traveled through temperature histories represented by vertical or near-vertical 1 ines extending from the horizontal axis to the data point.

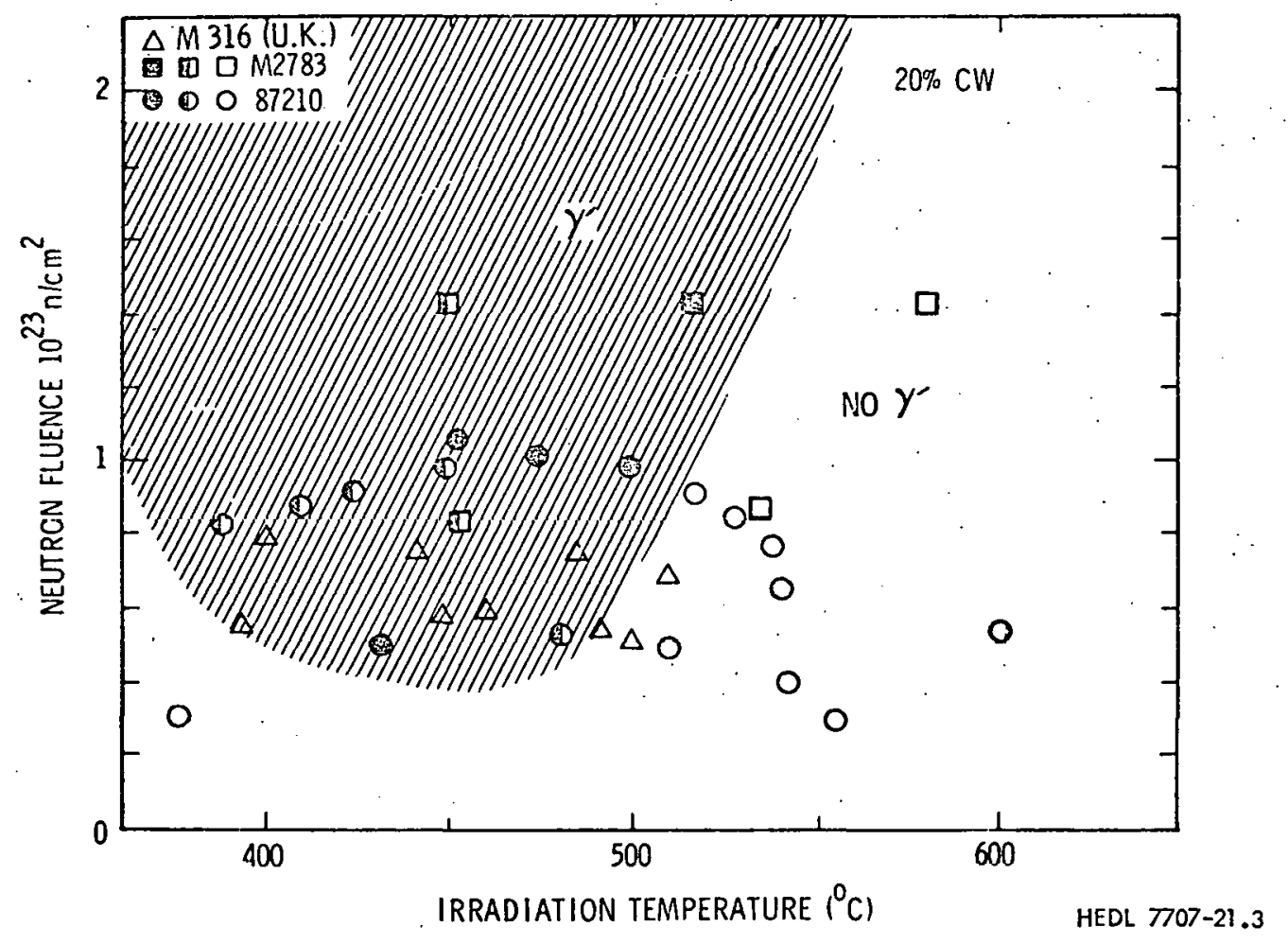

FIGURE 2. Irradiation Conditions for $\gamma^{\prime}$ Formation in Two Heats of $20 \%$ CW Als1 316. The 87210 heat shown is the same material used in the temperature change experiments described in this report. (5)

Figure 3 shows realistic temperature histories of various specimens during the irradiation. Since there was an interim examination of the subassembly at $6 \times 10^{22} \mathrm{n} / \mathrm{cm}^{2}$ ( $\mathrm{E}>0.1 \mathrm{MeV}$ ) it can be assumed that changes in temperature did nut occur until somewhere beyond $7 \times 10^{\text {? }} \mathrm{n} / \mathrm{cm}^{\text {? }}$. The decreases in temperature arose because the subcapsule was constructed of 


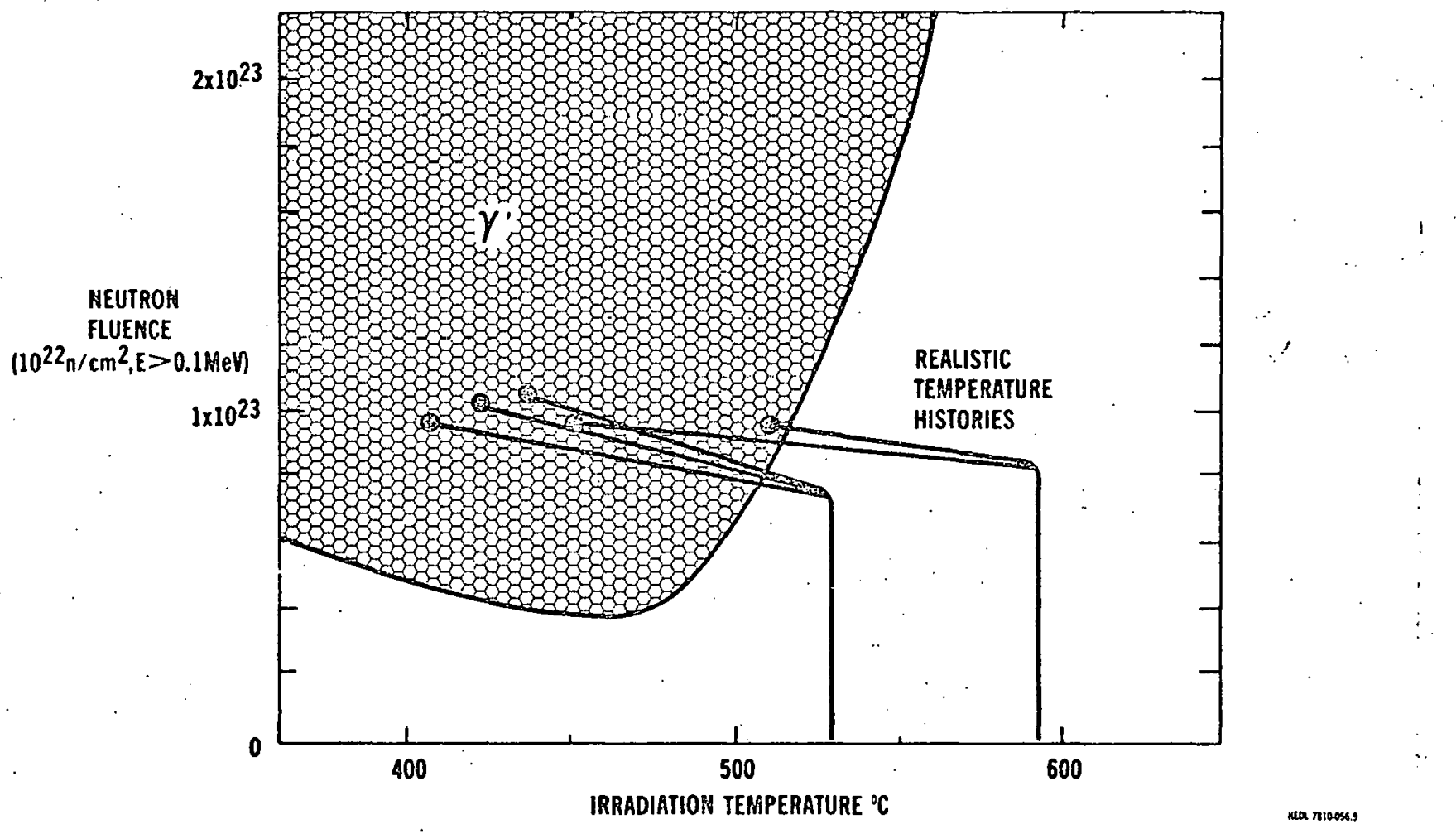

FIGURE 3. Typical Temperature Histories of Specimens Subjected to Gradual Temperature Reduction During Irradiation. 
15\% CW AISI 316 and was at a higher temperature than the $20 \%$ CW AISI 316 outer capsule. Both factors lead to a higher swelling rate for the inner capsule. Therefore, the thermal resistance of the gas gap decreased as the gap closed and the temperature in the subcapsule fell.

On the isothermal portion of each path it is known that carbosilicides (and possibly Laves phases at $585^{\circ} \mathrm{C}$ ) are forming. (6) When the temperature falls thereafter, the $\gamma^{\prime}$ phase begins to develop after the $\gamma^{\prime}$ phase boundary is passed. It appears from the accumulated data that the high temperature side of the boundary remains relatively fixed. Since all temperature histories appear to cross the boundary at about the same temperature and at not too dissimilar rates of temperature reduction $\mathrm{dT} / \mathrm{dt}$, it may be possible to correlate the two data sets starting at 525 and $585^{\circ} \mathrm{C}$ in terms of the amount of additional microchemical segregation that has occurred or the length of time since the $\gamma^{\prime}$ phase boundary was passed. If all curves have about the same value of $d T / d t$ beyond the phase boundary, then either of the above parameters should scale with the temperature difference measured from the boundary intercept.

It appears that two data points (designated $\ddot{A Q}$ and $B E$ ) must 1 ie just over the $\gamma^{\prime}$ boundary. There has been no significant amount of "excess" swelling in addition to the isothermal value (4\%), and yet the $\gamma^{\prime}$ phase was observed. Therefore the boundary intercept was specified to be $510^{\circ} \mathrm{C}$.

The data of Figure 1 have been replotted in Figure 4 . The isothermal values of swelling were assumed to be $S_{i}\left(525^{\circ} \mathrm{C}\right)=2.0 \%$ and $S_{i}\left(585^{\circ} \mathrm{C}\right)=4.0 \%$. The parameter on the $X$-axis is $\left(T_{f}-T_{B}\right)$, the difference between the final temperature and the boundary intercept temperature. There has been no normalization for fluence and stress differences although arrows show the anticipated movement of each data point if such a normalization was performed. In general, the stress-related corrections cancel out the filuence-related corrections.

Note that the two data sets coalesce into one, with only one nonconforming datum. More importantly, the data extrapolate back to the origin as would be expected frün the assumptions underlying the analysis. 


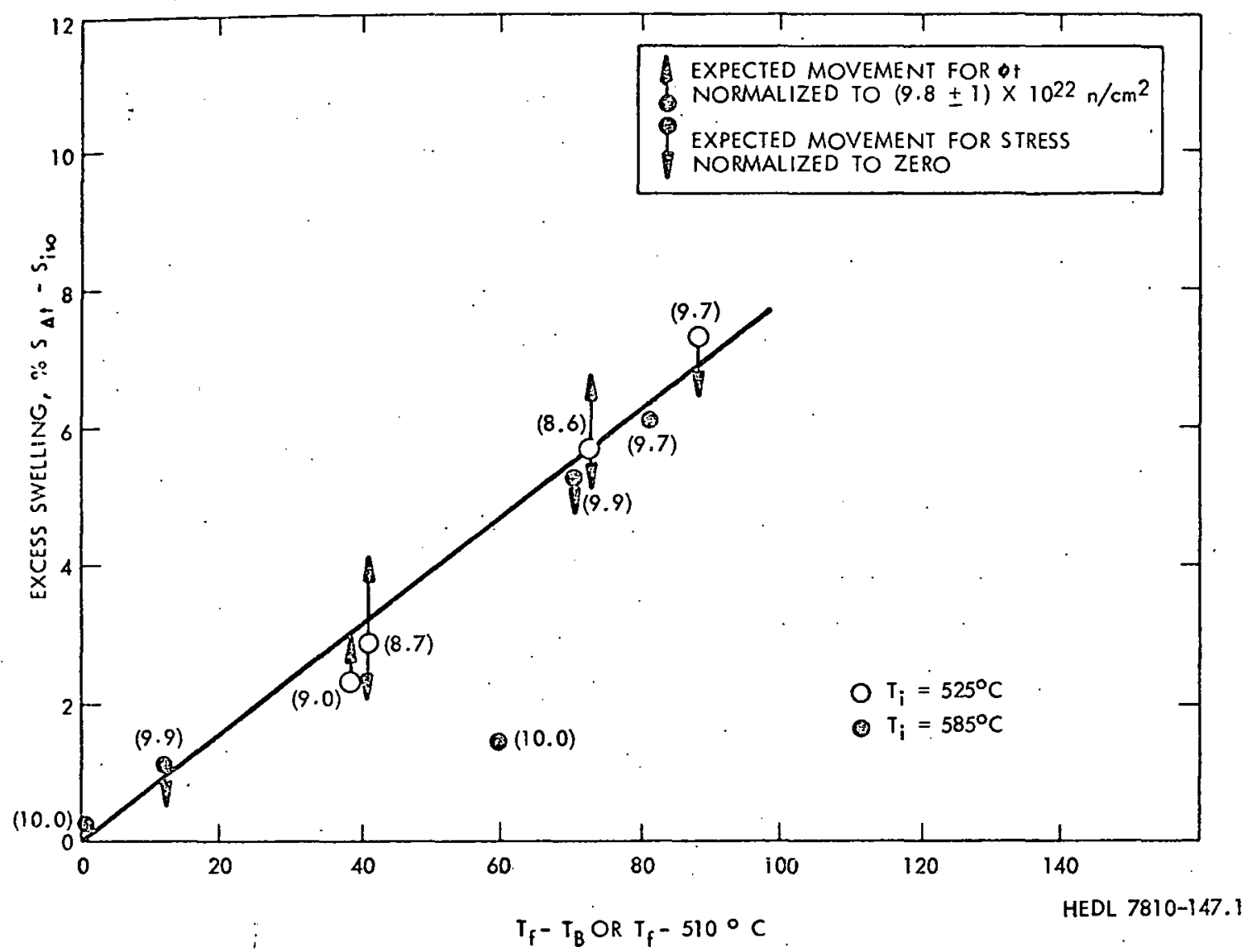

FIGURE 4. Correlation Between the Additional Swelling that Occurred in the P- 1 Experiment and the Temperature Drop Beyond the $\gamma$ ! Phase Intercept. Arrows pointing up represent the magnitude of data point movement if all data are normalized to $9.8 \pm 0.1 \times 10^{22}$. $\mathrm{n} / \mathrm{cm}^{2}$. Arrows pointing down reflect the magnitude of a correction to stress-free swelling.

This analysis is quite empirical in nature but its underlying assumptions are consistent with the body of evidence developed on the impact of the microchemical evolution on subsequent microstructural development. The major conclusion of all these studies is that the instantaneous swelling rate of this steel is governed more by the matrix composition than the concurrent void and dislocation microstructure. $(6,7)$

It should be emphasized, however; that the only. reason this analysis can be justified is that all specimen histories entered the isothermal $\gamma^{\prime}$ phase regime at essentially the same point and at essentially the same 
rate. If the data all had separate entry points it is not expected that such a correlation would be successful.

It is not known at this time whether the carbosilicides that developed during the isothermal portions of the diagram were stable at the lower temperatures. It is al so not known whether the $\gamma^{\prime}$ precipitation occurred primarily in the phase region next to the boundary or whether it was continuing even to the terminus of each temperature history.

\section{ENHANCED SWELLING IN ABRUPT TEMPERATURE CHANGE EXPERIMENTS}

Stress-relaxation experiments $(1)$ have been conducted on slit tube specimens constructed from the same heat of steel employed in the previous study. (2) Some of these specimens were subjected to abrupt temperature changes at $3 \times 10^{22} \mathrm{n} / \mathrm{cm}^{2} \quad(E>0.1 \mathrm{MeV})$ and irradiated thereafter only $0.35 \times 10^{22} \mathrm{n} / \mathrm{cm}^{2}$. As shown in Table 2 , the density changes indicate swelling only in those specimens which underwent a decrease in temperature. The: void contribution to density change, however, is on the same order of magnitude as the temperature-dependent precipitate-related densification that occurs in this steel. (10) While it is not completely certain that these smali strains can be confidently judged to show an effect of temperature change on swelling, it should be noted that the range of temperatures experienced by these specimens is consistent with the regime of the accelerated $\gamma$ ' mechanism. At the low fluence levels attained in the experiment one would not expeci $\gamma^{\prime}$ lu furm in this heat of steel, however.

TABLE 2

DENSITY CHANGES OBSERVED IN SLIT-TUBE EXPERIMENTS $(1)$

\begin{tabular}{|llllc|}
\hline \begin{tabular}{llll|} 
Prior irradiation \\
temperature
\end{tabular} & $\begin{array}{l}\text { Prior } \phi t \\
10^{22} \mathrm{n} / \mathrm{cm}^{2} \\
(E>0.1 \mathrm{MeV})\end{array}$ & $\begin{array}{l}\text { Reirradiation } \\
\text { temperature }\end{array}$ & $\begin{array}{l}\text { Additional } \phi t \\
10^{22} \mathrm{n} / \mathrm{cm}^{2} \\
(E>0.1 \mathrm{MeV})\end{array}$ & $\pi \mathrm{V}^{2} / \mathrm{V}^{\prime}$ \\
\hline- & - & $433^{\circ} \mathrm{C}$ & 0.35 & - \\
$391^{\circ} \mathrm{C}\left(735^{\circ} \mathrm{F}\right)$ & 2.98 & $\left(8.2^{\circ} \mathrm{F}\right)$ & 0.35 & -0.11 \\
$433^{\circ} \mathrm{C}\left(812^{\circ} \mathrm{F}\right)$ & 3.20 & & 0.35 & -0.06 \\
$510^{\circ} \mathrm{C}\left(950^{\circ} \mathrm{F}\right)$ & 3.20 & & 0.35 & 0.18 \\
- & - & $529^{\circ} \mathrm{C}$ & 0.35 & - \\
\hline $421^{\circ} \mathrm{C}\left(790^{\circ} \mathrm{F}\right)$ & 3.20 & $\left(985^{\circ} \mathrm{F}\right)$ & 0.35 & -0.02 \\
$510^{\circ} \mathrm{C}\left(950^{\circ} \mathrm{F}\right)$ & 3.20 & & 0.35 & -0.03 \\
$579^{\circ} \mathrm{C}\left(1075^{\circ} \mathrm{F}\right)$ & 3.20 & & 0.35 & 0.10 \\
\hline
\end{tabular}


ENHANCED SWELLING IN THE WSA-4 FUEL PIN EXPERIMENT

Foster and Boltax ${ }^{(3)}$ have reported that they observed a similar response to temperature change in the WSA-4 fuel subassembly test, where in some pins which were free to rotate in relatively large temperature gradients swelled more than those which rotated in very small gradients. The cladding of these pins was also constructed from the same heat of stee? employed in the two previous studies. Typical swelling profiles of such pins are shown in Figure 5.

It was also noted that the WSA-4 data at a starting temperature of $527^{\circ} \mathrm{C}$ tended to be consistent with the $\mathrm{X}-157$ pressurized tube data at the same starting temperature, as shown in Figure 6 . The slopes of curves of this type were found to be quite sensitive to irradiation temperature as shown in Figure 7 . The peak of this curve corresponds closely to the anticipated location of the $\gamma^{\prime}$ boundary. While its declining value on either side of the peak can be described in terms of the accelerated $\gamma^{\prime}$ model, the plateau at temperatures above $560^{\circ} \mathrm{C}$ is perplexing and cannot be related to any known phase changes.

It is important to note, however, that the temperatures used in this plot are life-averaged temperatures. Not only is there a temperature gradient in which the pin rotates, but the temperatures everywhere fall with increasing fluence and fuel burn-up. Figure 8 shows that the appropriate temperatures with which to compare the $P-1$ and WSA-4 data are the beginning-oflife inner channel temperature and the end-of-life outer channel temperature. This represents a better estimate of the total $\Delta T$ experienced by any portion of the pin cladding. The magnitude of the correction becomes increasingly larger for higher temperatures.

The numbered points on Figure 7 correspond to those 1 ife-averaged temperatures employed in the original analysis and the corresponding temperature histories are shown in Figure 9. Note that History \#3 is the first one to cross the $\gamma^{i}$ boundary, assumed again to be at $510^{\circ} \mathrm{C}$. For the accelerated $\gamma^{\prime}$ model, the portion of the total $\Delta T$ that lies below the boundary is the relevant parameter to plot against $d\left(\Delta V / V_{0}\right) / d(\Delta T)$. Note in Figure 7 that 


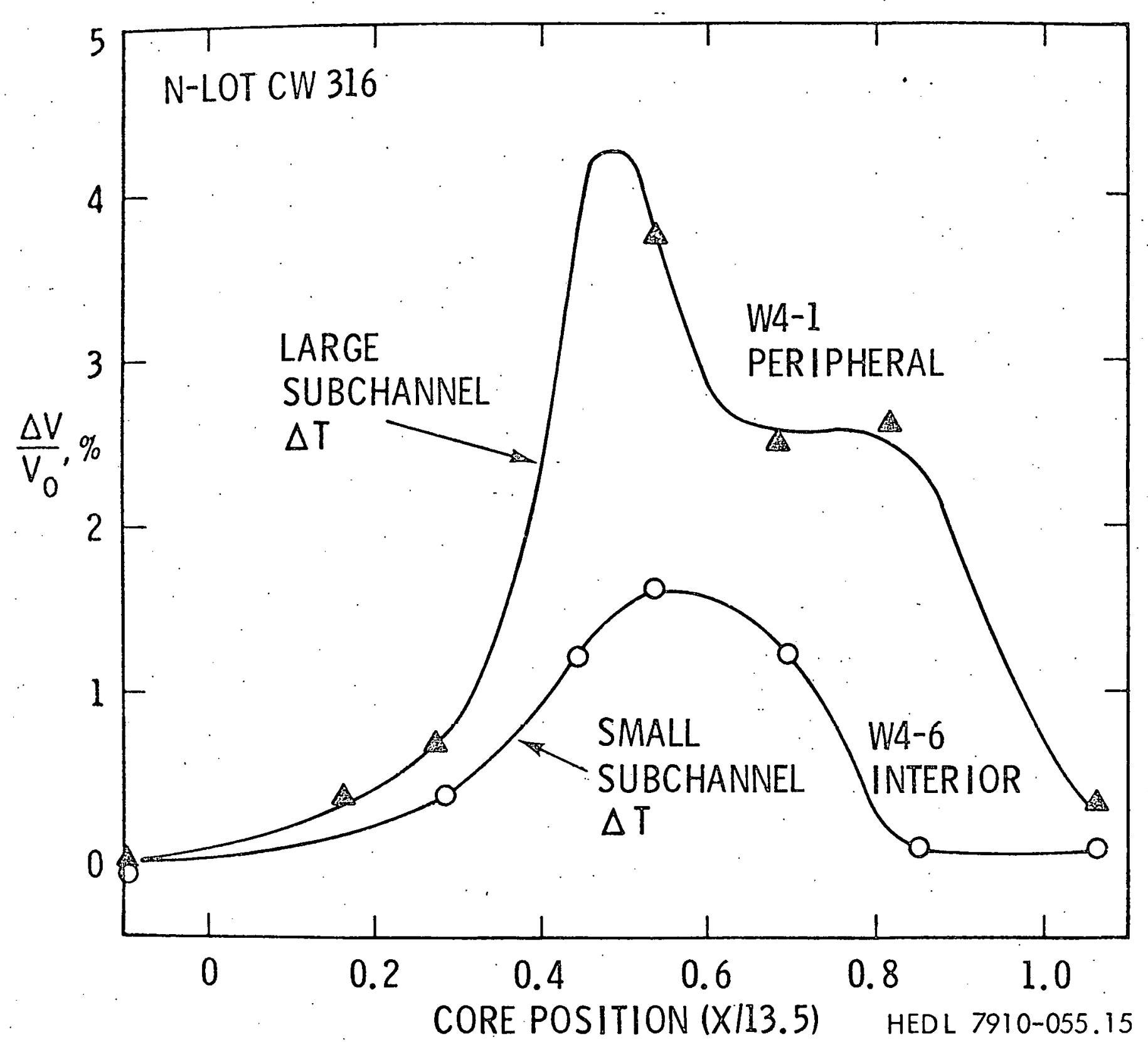

FIGURE 5. Swelling Observed in Cladding of Two WSA-4 Fuel Pins Showing Enhanced Swell ing When a Pin is Rotated in a Large Temperature Gradient. (3) The core position is given in terms of the core height of. 13.5 inches. 


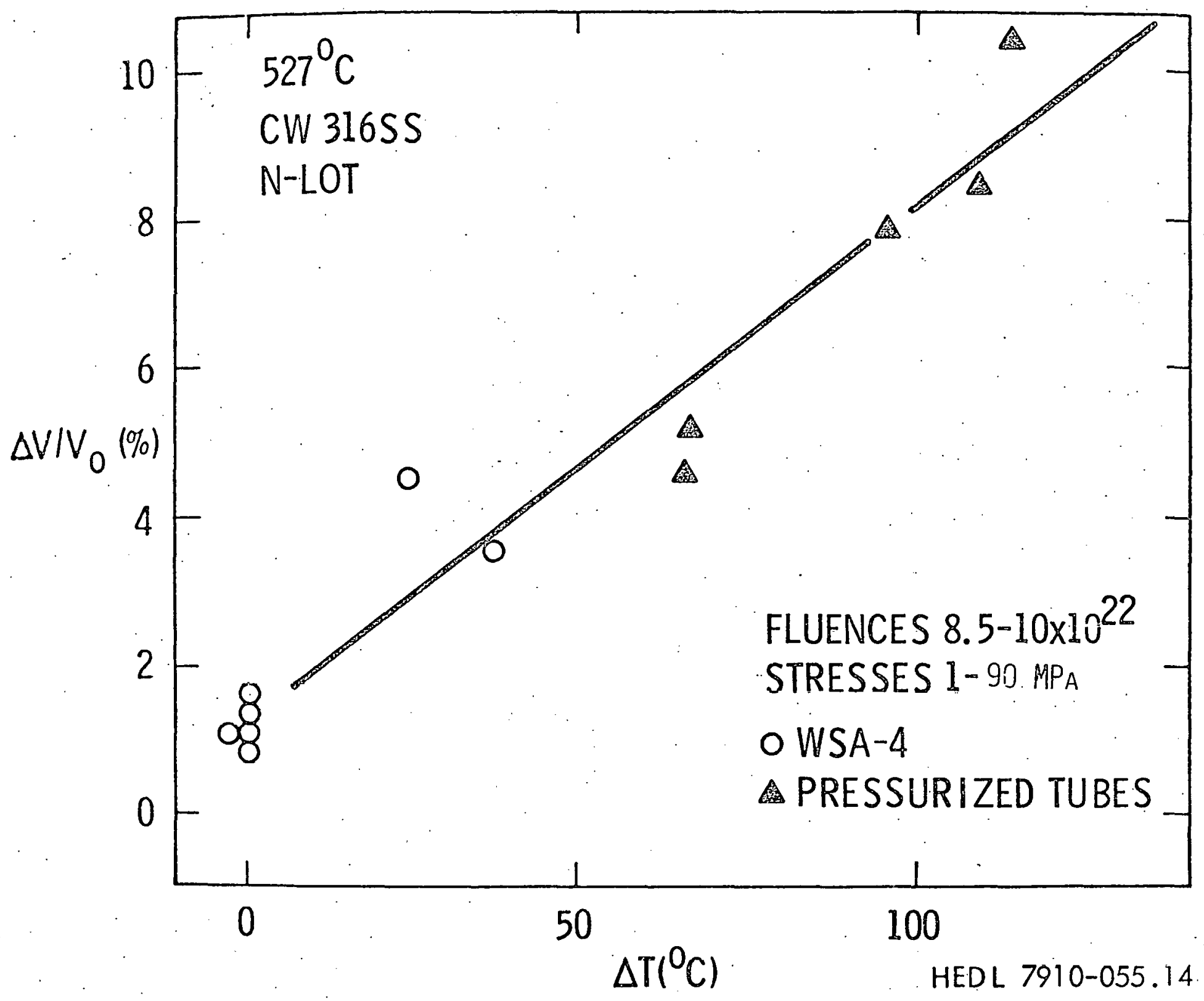

FIGURE 6. Comparison of Pressurized Tube and WSA-4 Cladding Data at $427^{\circ} \mathrm{C}$ ( 3 ) 


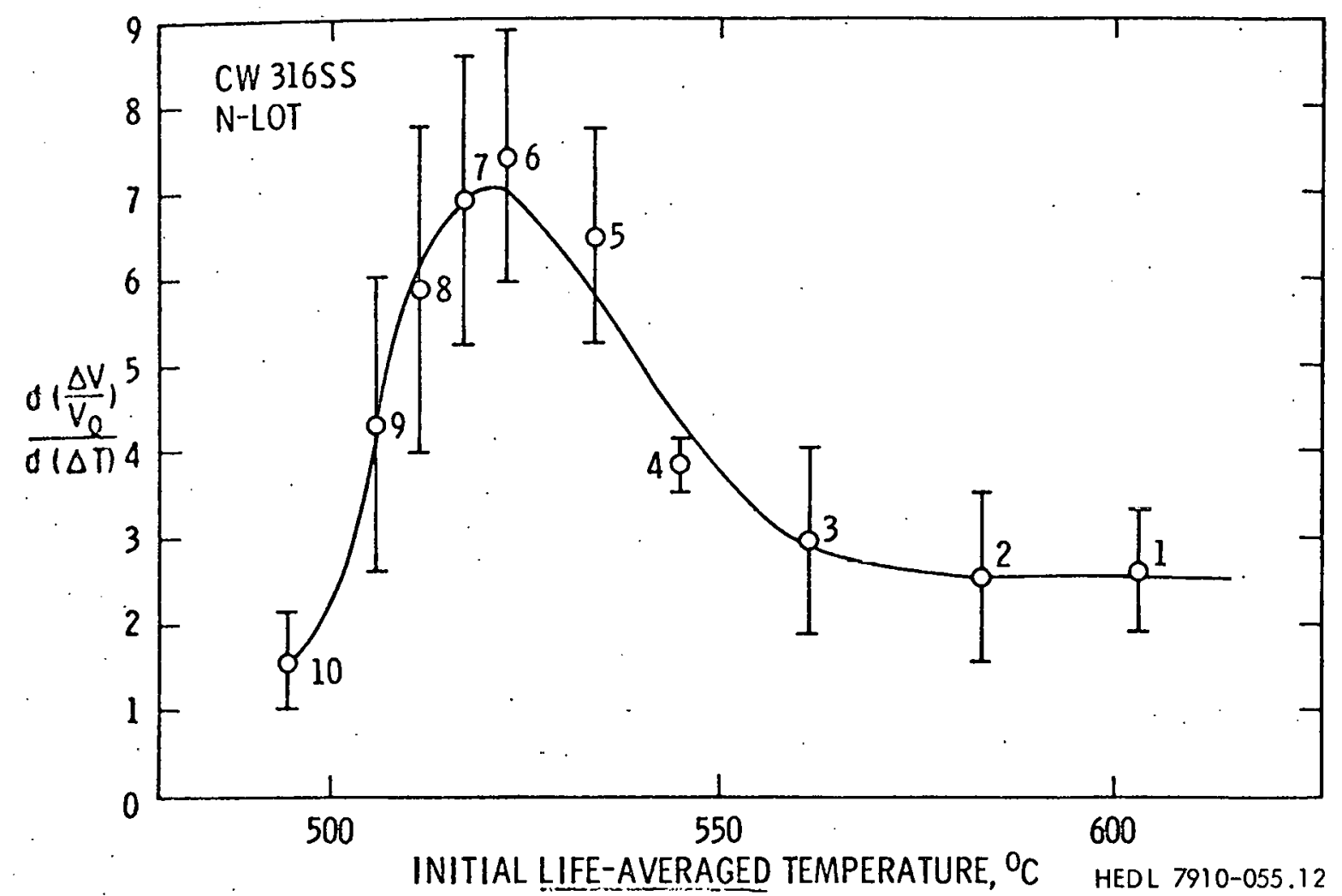

FIGURE 7. Temperature Dependence of the Slope of the Swelling Versus Temperature Decrease Effect observed in the WSA-4 Experiment. (3) LIFE-AVERAGED VALUES
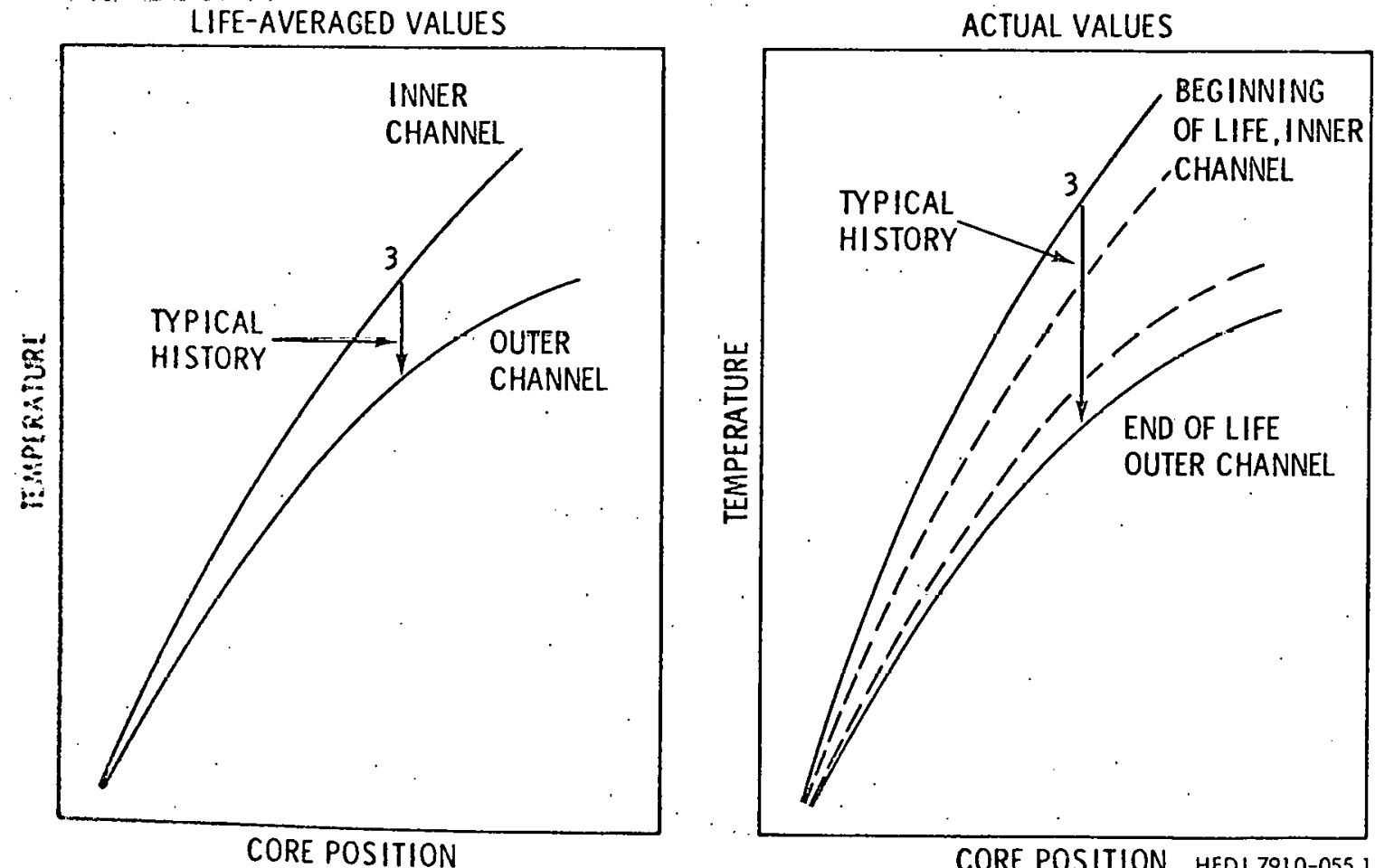

CORE POSITION HEDL7910-055.17

MCupe 3. Schematic Comparison of Temperature Histories Reported Earlier $(3)$ and Those Employed in This Report. 


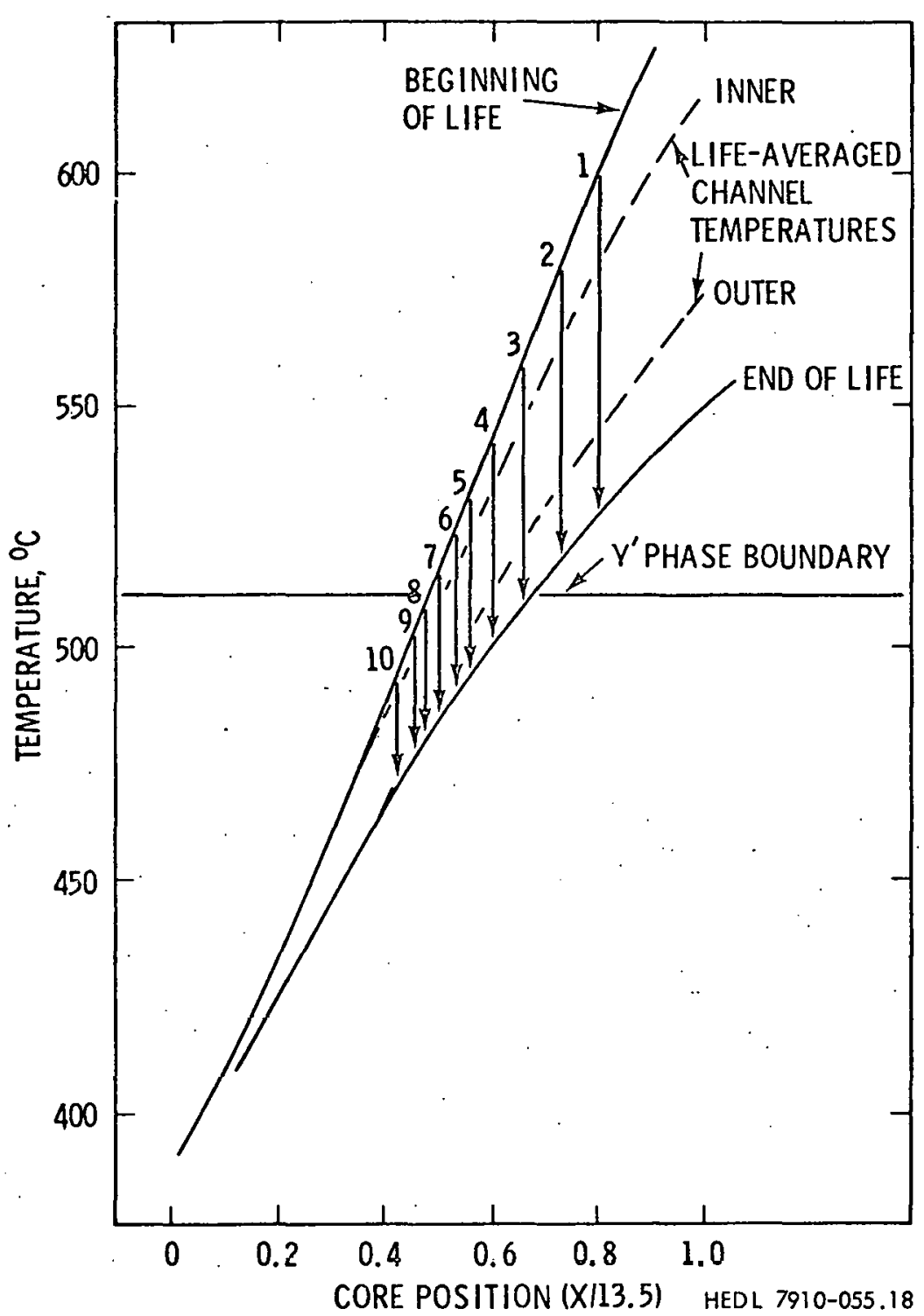

FIGURE 9. WSA-4 Temperature Histories Relevant to the Accelerated $\gamma^{\prime}$ Formation Model.

$\left(T_{f}-510^{\circ} \mathrm{C}\right)$ becomes increasingly larger until about $520^{\circ} \mathrm{C}$ and then shrinks thereafter as $\Delta T$ decreases.

Figure 10 shows a comparison of the earlier curve of Figure 7 and the. recalculated values. The plateau has now disappeared, indicating that no other phase transformations need to be invoked to explain the temperaturechange effect observed in the WSA-4 experiment. 


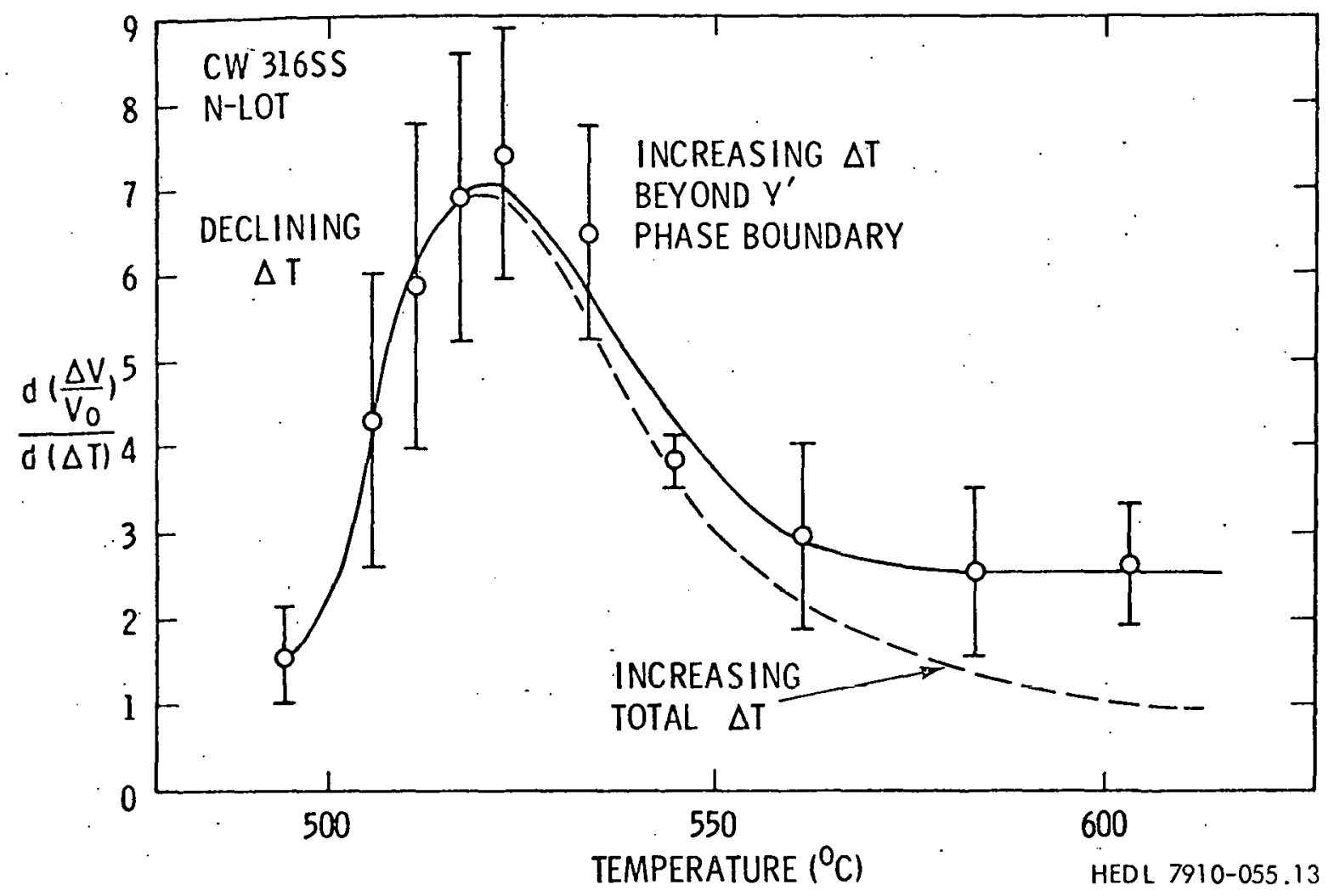

FIGURE 10. Comparison of the Recaliculated Temperature Dependence of Enhanced Swelling in the WSA-4 Experiment and That Reported Earlier. (3)

\section{EFFECT OF TEMPERATURE CHANGES ON IRRADIATION CREEP (P-1 EXPERIMENT)}

In the stress relaxation experiments described earlier it appeared that temperature changes of either sign had no measurable effect on the creep rate for the short fluence interval involved in the reirradiation. Since this ex- ; periment did not probe the fluence regime wherein the accelerated $\gamma^{\prime}$ mechanism would operate, no statement can be made from these data as to the effect of enhanced $\gamma^{\prime}$ formation on irradiation creep.

The best available test to address the possibility of enhanced creep lies in further analysis of the earlier data set of Bates and Gelles. These data were analyzed to compute the average creep coefficient $\bar{B}$ at a. total fluence of $1.0 \times 10^{23} \mathrm{n} / \mathrm{cm}^{2}$ ( $E>0.1$ MeV) and then compared to the isothe rmal values of $\bar{B}$ at the same fluence for the temperature range encompassing the $P-1$ data set. With the exception of one data point, corrections were made to account for the effect of stress on swelling. Figure 11 shows that 

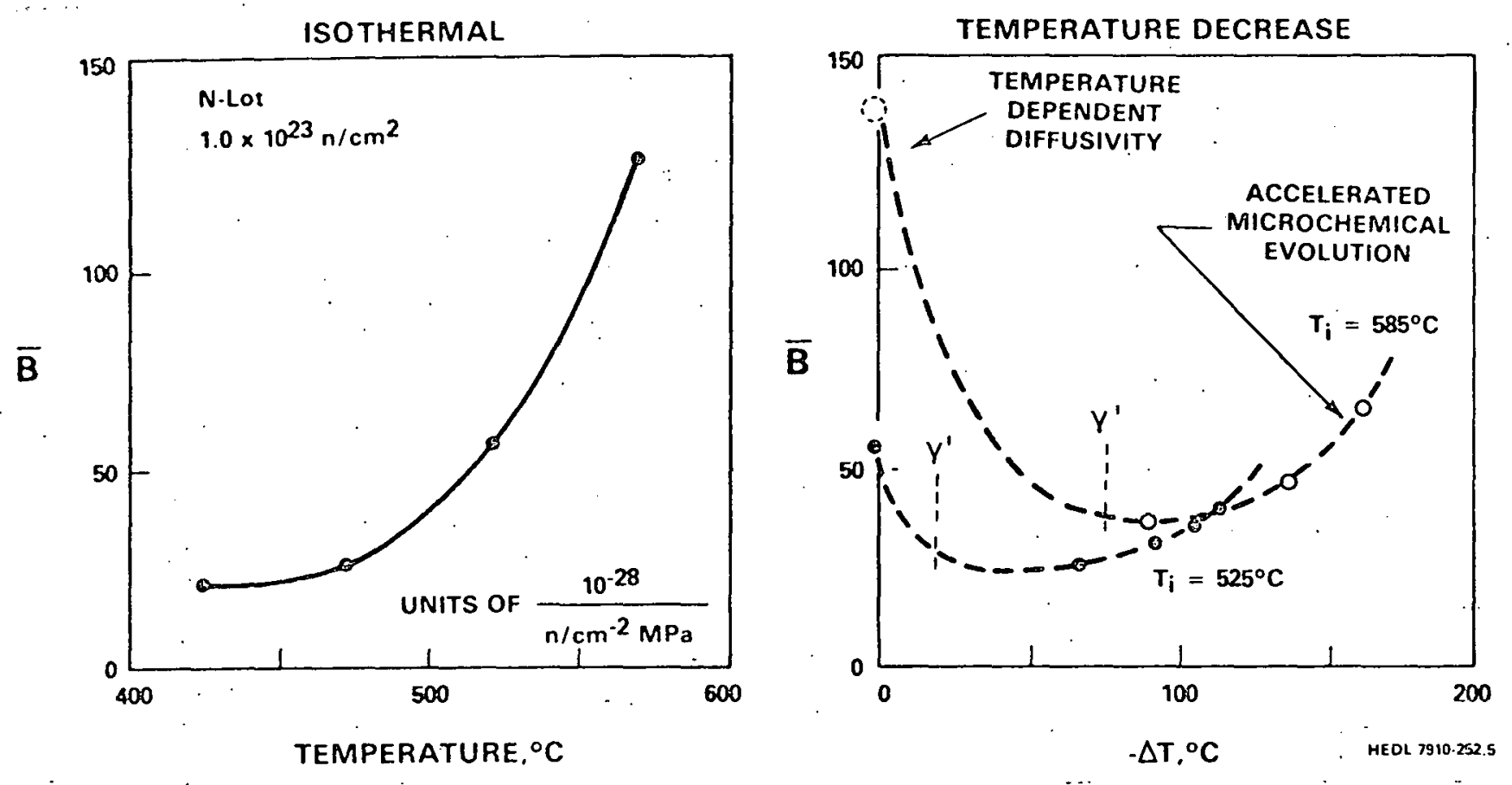

FIGURE 11. Comparison of Average Creep Coefficients of 20\% CW AISI 316 0btained in Response to Isothermal and Gradually Declining Irradiation Temperatures in the P-1 Experiment.

the $\bar{B}$ values obtained from irradiations involving temperature decreases fall steeply for low values of $\Delta T$ and then increase at higher $\Delta T$ values. Note that for each of the starting temperatures the reversal in the $\bar{B}$ curve occurs at about the point where the $\gamma^{\prime}$ phase is known to form.

The conclusion drawn from Figure 11 is that the creep rate initially falls as the temperature drops (in agreement with rate theory predictions for this temperature range for an alloy of constant composition) and then accelerates when the matrix composition changes strongly upon formation of $\gamma^{\prime}$. Whether one observes an increase or decrease in the average creep rate depends on when the observation is made. Unfortunately, the use of $\bar{B}$ coefficients rather than instantaneous creep rate coefficients tends to obscure this behavior. Figures 12 and 13 illustrate this point. The average creep coefficient over the fluence of $1.0 \times 10^{23} \mathrm{n} / \mathrm{cm}^{2}(E>0.1 \mathrm{MeV})$ appears to fall sharply in Figure 12 from the isothermal value when a substantial but gradual decrease in irradiation temperature occurs. Figure 13 shows, 


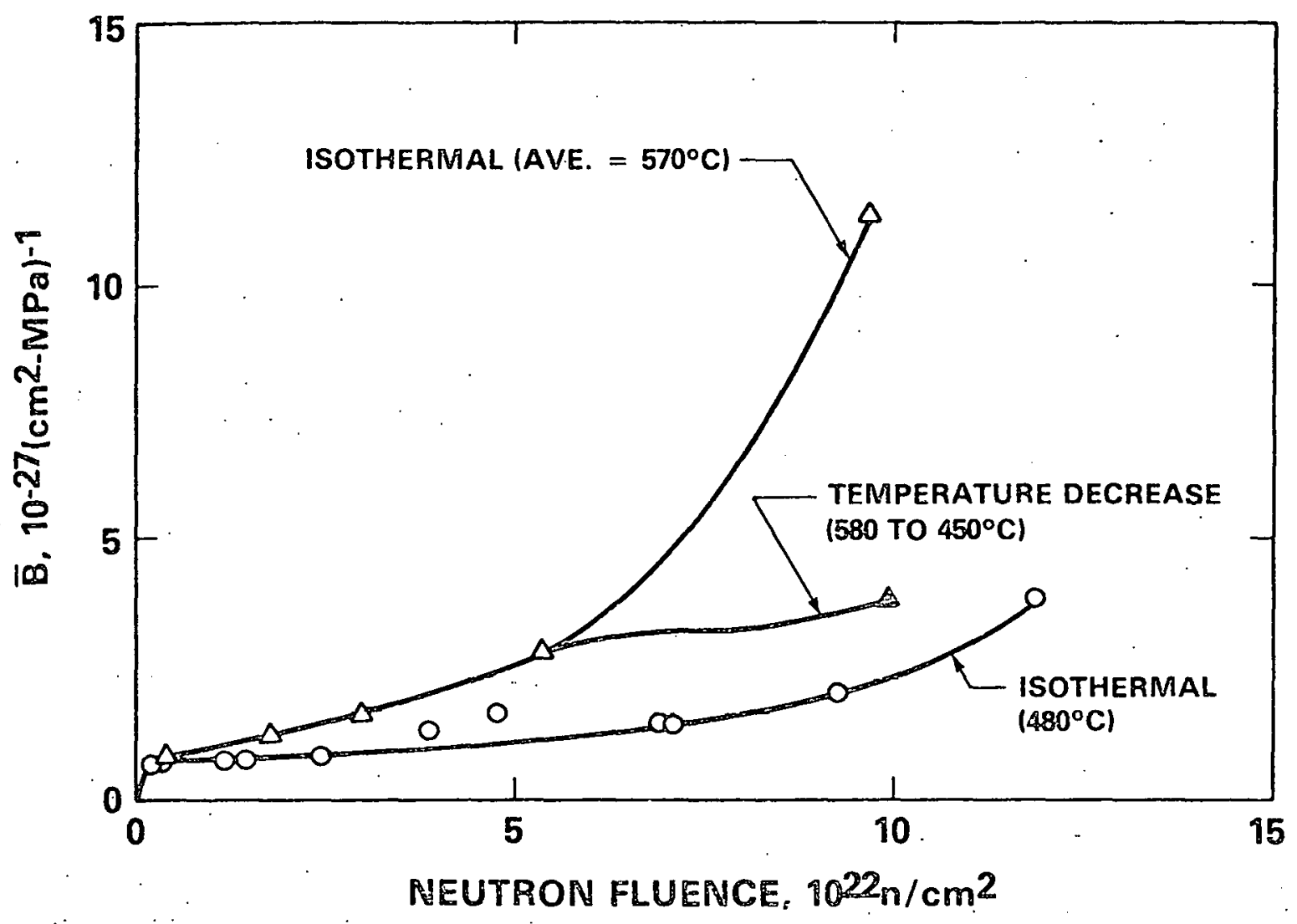

FIGURE 12. Effect of a Gradual Temperature Decreäse Beyond $6 \times 10^{22} \mathrm{n} / \mathrm{cm}^{2}$ on the Fluence Dependence of the Average Creep Coefficient.

however, that the $\bar{B}$ curve tends to obscure and de-emphasize the late-term acceleration of the instantaneous creep rate. This figure also shows that the actual rate can first fall sharply due to the temperature dependence of defect diffusivity and then increase with fluence and decreasing temperature due to the accelerated formation of the $\gamma^{\prime}$ phase. This reversal of behavior will not be reflected in the $\bar{B}$ curve when a gap of $5 \times 10^{22} \mathrm{n} / \mathrm{cm}^{2}$ exists between data points.

ENHANCED CREEP IN THE WSA-4 EXPERIMENT

Analysis of the creep strain data from the WSA-4 experiment is complicated by the presence of fuel-clad mechanical interaction, particularly at low temperatures. As shown in Figure 14, however, it appears that irradiation creep also increases when the irradiation temperature falls in a cyclical manner. The in-depth analysis of these data will be reported elsewhere. 


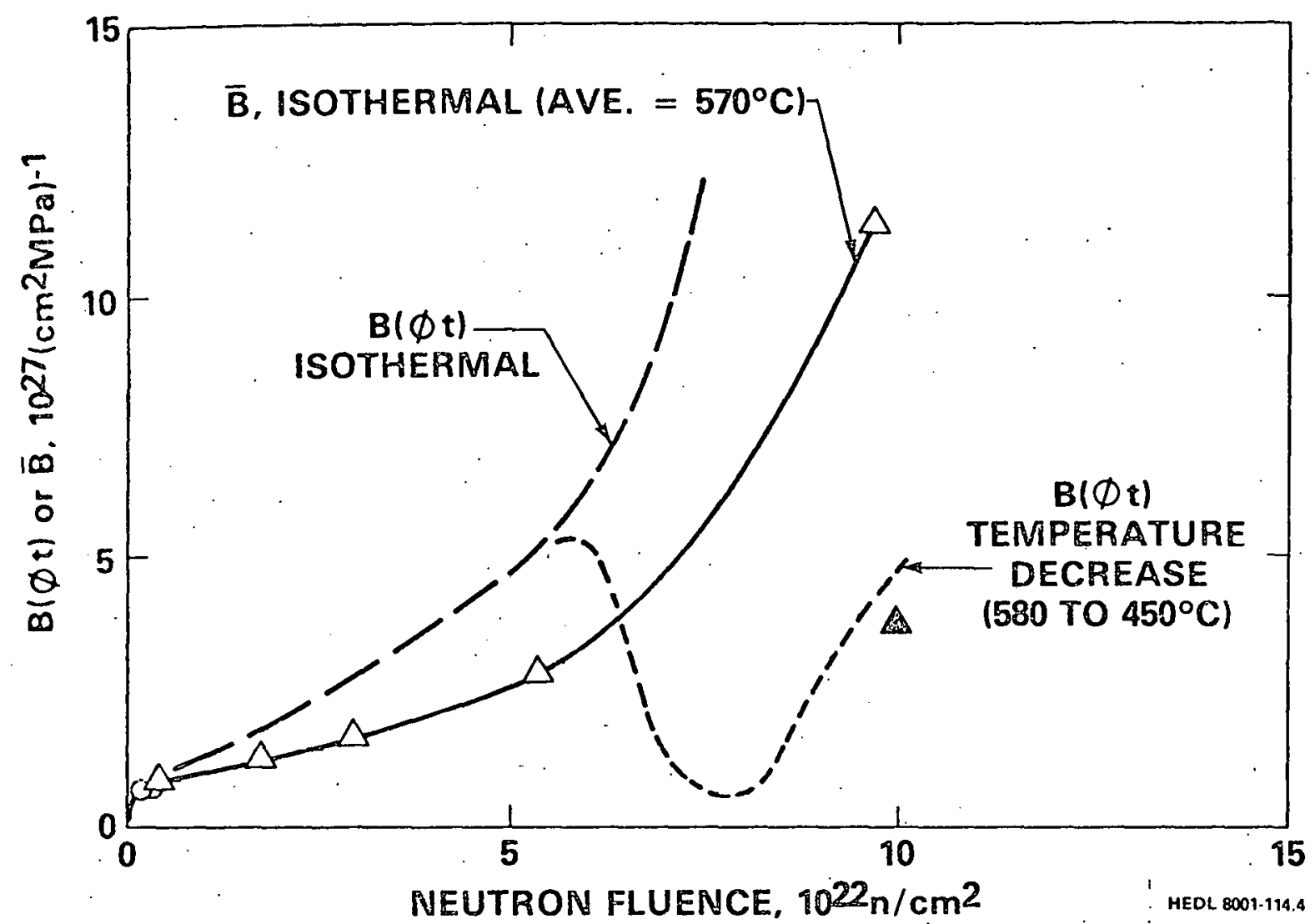

FIGURE 13. Schematic Illustration of the Relationship Between the Average and Instontaneous Creep Coefficients for the Data shown in Figure 12 .
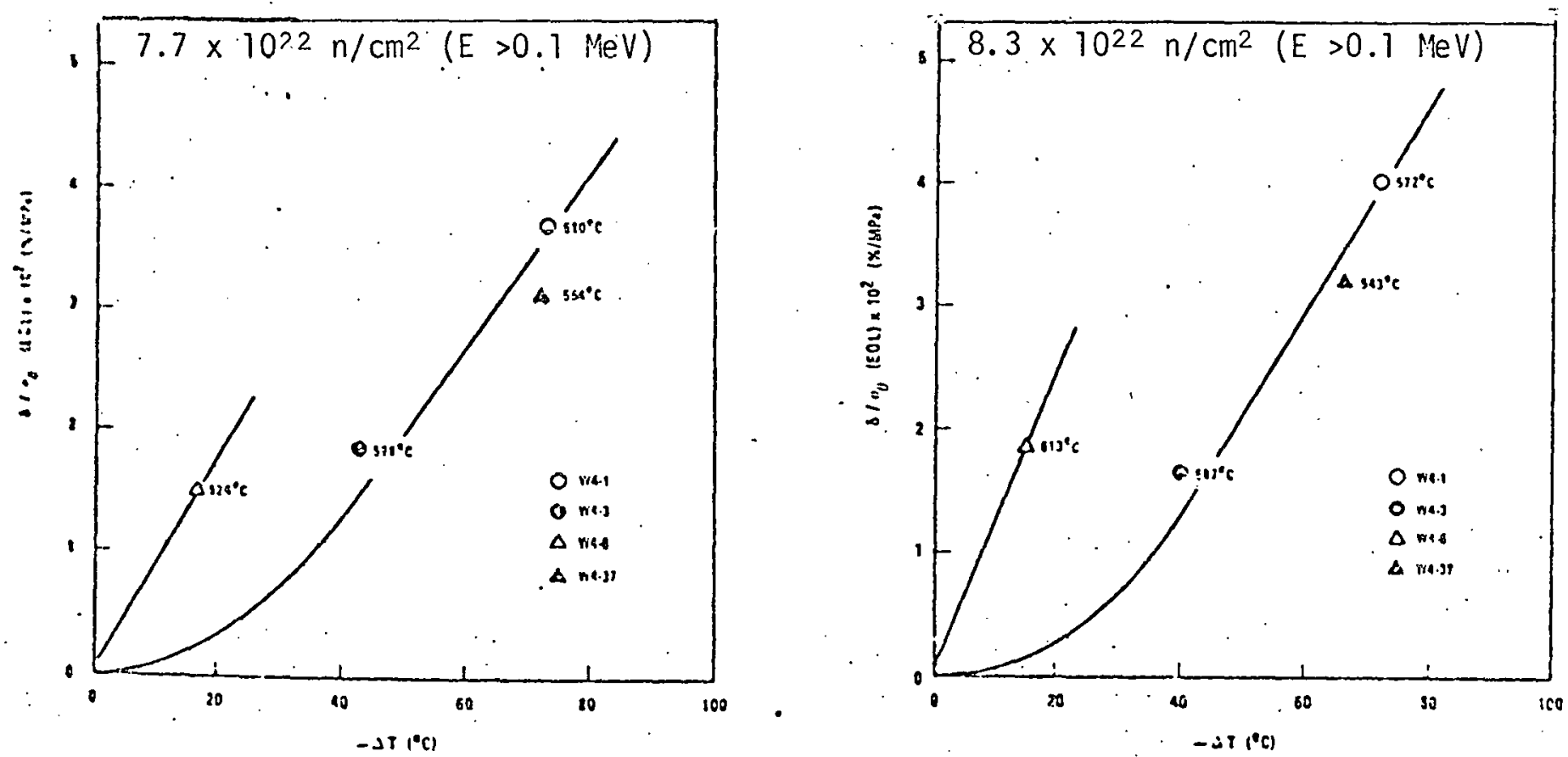

FIGURL 14. [nhanced Creep Strain Observed in WSA-4 Fue 1 Pin Cladding at 7.7 and $8.3 \times 10^{22} \mathrm{n} / \mathrm{cm}^{2}(E>0.1 \mathrm{MeV})$. 


\section{DISCUSSION}

It appears that the origin of the enhanced swelling and creep with decreasing temperature in $20 \%$ cold worked AISI 316 arises from the accelerated formation of the $\gamma^{\prime}$ phase and a concurrent short-circuiting of the normally sluggish microchemical evolution observed at temperatures below $550^{\circ} \mathrm{C}$. As reported elsewhere $(6,7,11)$ the removal of nickel and silicon (the primary constituents of the $\gamma^{\prime}$ phase) from the alloy matrix is a necessary precursor of swelling in this alloy. Although no data are currently available to document this prediction, it is expected that increasing temperature histories which first allow formation of $\gamma^{\prime}$ and later lead to its dissolution will cause a reduction in the swelling and creep rates of this alloy.

In the annealed condition of this steel another low temperature radiation-stable precipitate called G-phase forms which is also rich in nickel and silicon. $(7,11)$ It is anticipated that this phase will also be very sensitive to temperature history in the same manner as the $\gamma^{\prime}$ phase.

It is interesting to speculate on the possible origin of the path dependence of $\gamma^{\prime}$ formation. One possible $c l u e$ is found in the temperature dependence of nickel segregation to void surfaces. (11) Nickel appears to segregate to sinks at elevated temperatures due to the inverse Kirkendal 1 effect ${ }^{(12)}$ and would be relatively immobile as the temperature fell. Silicon does not segregate at high temperature, however. (11) since the formation of $\gamma^{\prime}$ requires the simultaneous segregation of both nickel and silicon, the decreasing temperature may provide conditions where the silicon can segregate to those sinks already enriched in nickel. It is expected that silicon would segregate at lower temperatures by the interstitial-solute drag mechanism.

There also may be some compositional considerations which affect the rate of $\gamma^{\prime}$ formation, however. In earlier comparative irradiations of annealed, cold-worked and cold-worked and aged AISI 316 it was shown that aging produced the normal carbide and Laves phases, but subsequent irradiation of the aged steel at low irradiation temperature led to the accelerated formation of the normaily sluggish $\gamma^{\prime}$ phase. (6) The major consequence of this precipitation behavior was the generation of even more swelling than 
observed in the annealed steel. Perhaps molybdenum or some other element must be concentrated in the carbide and Laves phases prior to the onset of $\gamma^{\prime}$ formation.

One additional conclusion concerning development of swelling correlations must be drawn from the data analyzed in this study. The large values of swelling observed for large temperature decreases cannot be explained by any small modification of the currently available empirical descriptions of isothermal swelling. (13) In particular, the "steady-state" swelling rates contained in these correlations must be changed to reflect the possibility that the low swelling rates observed in cold-worked AISI 316 are merely a manifestation of a very slowly evolving precipitate microstructure, but one that can be short-circuited by certain temperature histories.

CONCLUSIONS

The swelling and irradiation creep of $20 \%$ cold-worked AISI 316 is sensitive to the temperature history experienced by the alloy both in and out of reactor. The primary sensitivity appears to be in the rate of formation of the $\gamma^{\prime}$ phase. The onset of this phase is accelerated by in-reactor reductions in temperature and leads to enhanced levels of creep and swelling.

\section{REFERENCES}

1. B. A. Chin and J. L. Straalsund, J. Nucl. Mat., 74, 260 (1978).

2. J. F. Bates and D. S. Gelles, J. Nucl. Mat., 7l, 365 (1978).

3. J. P. Foster and A. Boltax, Nucl. Tech., 47, 181 (1980).

4. E. R. Gilbert and B. A. Chin, ANS TRANS., 28, 147 (1978).

5. H. R. Brager and F. A. Garner, J. Nucl. Mat., 73, 9 (1978).

6. H. R. Brager and F. A. Garner, "Dependence of Void Formation of Phase Stability in Neutron Irradiated Type 316 Stainless Steel," Proceedings, International Symposium on Effects of Radiation on Structural Materials, Richland, Washington (July 10, 1978).

7. H. R. Brager and F. A. Garner, "Microchemical Evolution of NeutronIrradiated AISI 316 ," this conference.

8. F. A. Garner, E. R. Gilbert and D. Porter, "Stress-Enhanced Swelling of Metals During Irradiation, "this conference. 
9. C. Cawthorne and C. Brown, J. Nucl. Mat., 66, 201 (1977).

10. F. A. Garner, W. V. Cummings, J. F. Bates and E. R. Gilbert, "Densification-Induced Strains in 20\% Cold-Worked 316 Stainless Steel During Neutron Irradiation," HEDL-TME 78-9 (June 1978).

11. H. R. Brager and F. A. Garner, "Analysis of Radiation-Induced Microchemical. Evolution in 300 Series Stainless Steels," HEDL-SA-1883, presented at the AIME Symposium on Advanced Techniques for the Characterization of Irradiated Materials, Las Vegas, Nevada (February 24-28, 1980).

12. A. D. Marwick, R. C. Pillar and P. M. Sival1, J. Nucl. Mat., 83, 35 (1979).

13. J. F. Bates and M. K. Korenko, "Empirical Development of IrradiationInduced Swelling Design Correlation," to be published in. Nlucl. Tech: 
AUTHORS

F. A. Garner

Fellow Scientist

Hanford Engineering Development Laboratory

Richland, WA 99352

E. R. Gilbert

Senior Scientist

Hanford Engineering Development Laboratory Richland, WA 99352

D. S. Gelles

Senior Scientist

Hanford Engineering Development Laboratory Richland, WA 99352

J. P. Foster

Senior Scientist

Westinghouse Electric Corporation

Advanced Reactors Division

Madison, PA 15663.

Key words: Radiation, fast reactors, swelling, voids, irradiation creep, phase stability, temperature and temperature history. 